\title{
Why long-term therapy matters
}

\author{
Jeremy Holmes
}

A report in The Times of 14 October 1997 announced: "Shrinks gripped by anxiety crisis in feelgood New York". New York therapists, previously sitting on an analytic gold-mine, have never had it so bad: fewer patients overall, and especially a decline in intensive analytic cases. In 1977 the average analyst had three, three times a week, cases; now it is no more than one. Various explanations are put forward for these 'facts' (no sources are offered). First, in the wake of several debunking biographical studies, there is a general scepticism about Freudian theory and the integrity of its founding father. Second, the rise of managed care means that insurance companies set strict limits on reimbursements, with each case rigorously scrutinised by 'thirdparty' care managers. Third, the advent of timelimited therapies such as cognitive therapy, and the selective serotonin reuptake inhibitors, means that psychoanalysis is no longer the "only game in town" (Eisenberg, 1986). Finally, a Clintonesque 'feelgood factor' means that the new rich would rather spend their money on pizzas and skiing holidays than analysis: retail therapy has superseded real therapy.

There is more than a whiff of triumphalism in this report, contributing to an anti-analytic atmosphere, from which the UK, including the Royal College of Psychiatrists, is not immune. How seriously should we take such broadsides, or, as analysts would put it, envious attacks? It might be argued that a bit of psychoanalysis knocking is fairly harmless, and given the phenomenal success of the psychoanalytic movement, may be no more damaging than the recent mini-crash in the stock market, which supposedly took the froth out of the system, but still left shares at a higher level than at the start of the year. As a National Health Service psychoanalytic psychotherapist, I find such slurs worrying. Within the new-style College the psychotherapy faculty has work to do in defining its role, and in promoting psychotherapeutic pluralism by bringing cognitive-behavioural therapy and systemic therapies further into the fold, but this will not be achieved at the expense of the psychoanalytic contribution.

The limitations of time-limited therapies are increasingly apparent, and a recent consumer survey (Seligman, 1995) confirmed Orlinsky et als (1994) dose-effect curve, showing that longer therapies produce better outcomes and more client satisfaction. More than ever, trainees need the experience of long-term dynamic therapy under supervision if they are to be equipped for the implications of their role as consultants at the still point of a turning world of mental health care. Contemporary psychiatry desperately needs the understanding of group processes and transference and countertransference implications of working with personality disordered patients that psychoanalytic thinking uniquely can provide.

The UK-based International Journal of Psychoanalysis, under the inspiring editorship of David Tuckett, is one example of how psychoanalysis is beginning to put its house in order, opening itself to developments in neurobiology and the new psychology, and recognising the role of psychoanalytic psychotherapy as well as pure psychoanalysis. It would be a tragedy if the prejudicial attitudes so beloved of the popular press helped close the collective mind of the College to the role of dynamic psychiatry. Are we prepared to settle for a role as pill-pushers and form-fillers? Would we not rather be at the cutting edge of a psychiatry for the 21 st century that brings together meaning and mechanism, the uniqueness of the individual and sophisticated systems of classification, narrative-based and evidencebased medicine, the psychotherapies and pharmacotherapy, into a new synthesis? Let us thunder against the thunderer, and not succumb to Big Apple bunkum!

\section{References}

EISENBERG. L. (1986) Mindlessness and brainlessness in psychiatry. British Journal of Psychiatry. 148, 497-508.

ORLINSKY, D.. GRAW, K. \& PARKS, B. (1994) Process and outcome in psychotherapy - noch einmal. In Handbook of Psychotherapy and Behaviour Change. (eds S. Garfield \& A. Bergin) (4th edn). pp. 270-378. Chichester: Wiley.

Seugman, M. (1995) The effectiveness of psychotherapy. The consumer report. American Psychologist. 60. 965-974.

Jeremy Holmes, Consultant Psychiatrist/ Psychotherapist, Northern Devon Healthcare NHS Trust, Northern Devon Healthcare, North Devon District Hospital, Raleigh Park. Barnstaple, Devon EX31 4JB 